\title{
Spatio-temporal variation in malaria transmission intensity in five agro-ecosystems in Mvomero district, Tanzania
}

\author{
Leonard E. G. Mboera ${ }^{1}$, Kesheni P. Senkoro ${ }^{1}$, Benjamin K. Mayala ${ }^{1}$, Susan F. Rumisha ${ }^{1}$, \\ Rwehumbiza T. Rwegoshora ${ }^{2 \dagger}$, Malongo R. S. Mlozi ${ }^{3}$, Elizabeth H. Shayo ${ }^{1}$ \\ ${ }^{1}$ National Institute for Medical Research, P.O. Box 9653, Dar es Salaam, Tanzania; ${ }^{2}$ Amani Medical \\ Research Centre, P.O. Box 81, Muheza, Tanzania; ${ }^{3}$ Sokoine University of Agriculture, P.O. Box 3002, \\ Morogoro, Tanzania; ${ }^{\dagger}$ Deceased
}

\begin{abstract}
In Africa, malaria is predominantly a rural disease where agriculture forms the backbone of the economy. Various agro-ecosystems and crop production systems have an impact on mosquito productivity, and hence malaria transmission intensity. This study was carried out to determine spatial and temporal variations in anopheline mosquito population and malaria transmission intensity in five villages, representing different agro-ecosystems in Mvomero district, Tanzania, so as to provide baseline information for malaria interventions. The agro-ecosystems consisted of irrigated sugarcane, flooding rice irrigation, non-flooding rice irrigation, wet savannah and dry savannah. In each setting, adult mosquitoes were sampled monthly using Centers for Disease Control and Prevention (CDC) light traps from August 2004 to July 2005. A total of 35,702 female mosquitoes were collected. Anopheles gambiae sensu lato was the most abundant $(58.9 \%)$ mosquito species. An. funestus accounted for $12.0 \%$ of the mosquitoes collected. There was a substantial village to village variation and seasonality in the density of Anopheles mosquito population, with peaks in May towards the end of the warm and rainy season. Significantly larger numbers of anophelines were collected from traditional flooding rice irrigation ecosystem $(70.7 \%)$ than in non-flooding rice irrigation $(8.6 \%)$, sugarcane $(7.0 \%)$, wet savannah $(7.3 \%)$ and dry savannah $(6.4 \%)$. The overall sporozoite rates for An. gambiae and An. funestus were $3.4 \%$ and $2.3 \%$, respectively. The combined overall sporozoite rate (An. gambiae+An. funestus) was $3.2 \%$. The mean annual entomological inoculation rate (EIR) for An. gambiae s.l. was 728 infective bites per person per year and this was significantly higher in traditional flooding rice irrigation (1351) than in other agro-ecosystems. The highest EIRs for $A n$. gambiae s.l. and An. funestus were observed during May 2005 (long rainy season) and December 2004 (short rainy season), respectively. The findings support the evidence that malaria transmission risk varies even between neighbouring villages and is influenced by agro-ecosystems. This study therefore, demonstrates the need to generate spatial and temporal data on transmission intensity on smaller scales taking into consideration agro-ecosystems that will identify area-specific transmission intensity to guide targeted control of malaria operations.
\end{abstract}

Keywords: agro-ecosystem, Anopheles gambiae, Anopheles funestus, geographical information system, malaria, Tanzania.

\section{Introduction}

In Africa, malaria is predominantly a rural disease where agriculture forms the backbone of the econo-

Corresponding author:

Leonard E. G. Mboera

National Institute for Medical Research

P.O. Box 9653, Dar es Salaam, Tanzania

Tel. +255 222121400 Fax +25522 2121360

E-mail: 1mboera@nimr.or.tz my. Various crop production systems, especially, where irrigation is the practice, are known to provide suitable microhabitats for adult mosquitoes, and hence have an impact on malaria transmission intensity. Generally, higher malaria prevalence has been reported in villages with irrigated than without irrigated agriculture. This is because crop irrigation is known to lead to a sharp rise in mosquitoes, and hence increased malaria transmission (WHO/FAO/ UNEP, 2008). Rice, sugarcane, wheat, cotton and 
vegetables are the major crops under irrigation in Africa. Of these crops rice is considered to pose the greatest danger to health as it is grown in flooded conditions, which provide ideal breeding sites for malaria mosquitoes (Ijumba and Lindsay, 2001).

There is a paucity of data on the impact of other agro-ecosystems on malaria transmission in Africa with only a few studies on malaria among communities in sugarcane plantations and those producing cotton and vegetables (Packard, 1986; Ijumba, 1997; Shililu et al., 2003; Dongus et al., 2009). Studies in Kenya have reported a high sporozoite rate for Anopheles gambiae suggesting a high malaria transmission level in the area and low but perennial malaria transmission intensity in sugarcane growing zone (Githeko et al., 1993). In Sudan, an increase in malaria transmission has been reported to be associated with the cotton irrigation scheme in the Gezira-Managil (Oomen et al., 1988). Recently, irrigated, open-spaced, commercial vegetable production has also been associated with malaria in urban areas of Accra, Ghana (Klinkenberg et al., 2005).

Variations in mosquito density and entomological inoculation rate (EIR) in relation to agro-ecosystems have been reported in northern Tanzania and northern Ghana (Ijumba and Lindsay, 2001; Appawu et al., 2004). In Tanzania, Ijumba and Lindsay (2001) observed that the potential risk of malaria due to An. arabiensis and An. funestus was four-fold higher in rice-field villages than in sugarcane or savannah villages nearby. In the Ghana study (Appawu et al., 2004) a higher intensity of malaria transmission among individuals in irrigated communities than in the non-irrigated ones was reported. However, the study in northern Tanzania showed that improved socio-economic status due to rice growing lead to reduced malaria prevalence, in spite of increased mosquito populations (Ijumba and Lindsay, 2001). Similarly, a study in Kenya has shown that malaria prevalence is lower in irrigated villages, as a result of widespread use of bednets and antimalarial drugs (Mutero et al., 2006).

The enormous heterogeneity in malaria transmis- sion intensity in Africa calls for targeted malaria control interventions that require an understanding of the forces that drive transmission. The understanding of indices relating to malaria transmission is central to its control through quantifying the potential risk of infection and elucidating the patterns of disease transmission (Githeko et al., 1993). This calls for the need to accurately determine the spatial and temporal variations in malaria transmission within localized areas that will target specific needs in malaria interventions. In this study, we examined the spatial and temporal heterogeneity in malaria transmission in five villages representing different agro-ecosystems in Mvomero district, Tanzania, to provide baseline information for malaria interventions.

\section{Materials and methods}

\section{Study area and agro-ecosystems}

This study was carried out in Mvomero district

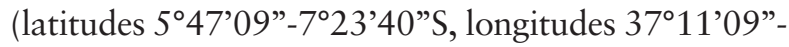
$\left.38^{\circ} 01^{\prime} 33^{\prime \prime} \mathrm{E}\right)$, in Tanzania covering an area of 7,325 $\mathrm{km}^{2}$. The district lies on the foothills of Nguru Mountains to the north-west and Uluguru Mountains to the south-east. The study was carried out in five villages namely: Mtibwa, Komtonga, Mkindo, Dakawa and Luhindo. The study area lies at altitudes ranging between 293 and $379 \mathrm{~m}$ above sea level (asl) within the Wami River basin. The villages were approximately $8-11 \mathrm{~km}$ from one another.

More than $80 \%$ of adult population in Mvomero earns their livelihood from agriculture, though mainly at subsistence production. Monoculture, mixed cropping and multiple cropping are common. The average farm size varies with the type of cropping system, which in turn varies from village to village. The locations of the agro-ecosystems and villages were georeferenced using a hand-held global positioning system (GPS) receiver. The coordinates of the variables were imported into a geographical information system (GIS) database in which they were converted into a point map by Arc 
GIS software (ESRI, Redlands, CA, USA). The study area was stratified into five agro-ecological systems (Fig. 1) and covered approximately an area of $1,300 \mathrm{~km}^{2}$.

Mtibwa village $\left(6^{\circ} 08^{\prime} 20^{\prime \prime} \mathrm{S}, 37^{\circ} 38^{\prime} 16^{\prime \prime E}\right.$; altitude $=379 \mathrm{~m}$ asl) forms the furthest north point of the study area and borders the Nguru Mountains. Mtibwa area is relatively more developed compared to many rural areas in Tanzania following the establishment of the sugar-processing factory in the early 1960s. Mtibwa sugarcane scheme is the largest sugarcane estate in Tanzania. The scheme is irrigated by use of overhead sprinklers or by open earth-lined and gravity-fed irrigation canals.
Human houses are within the plantation and surrounded by sugarcane in all sides.

Komtonga village $\left(6^{\circ} 09^{\prime} 54^{\prime}\right.$ 'S, 37 $35^{\prime} 06^{\prime} \mathrm{E}$; altitude $=305 \mathrm{~m}$ asl) is characterised by swampy flatland lying on the tributaries of Wami River. Most of the communities in this village are small-scale farmers of rice using the traditional ground flooding irrigation practice. Human habitations are located at about 50-100 $\mathrm{m}$ north-west of the rice fields.

Mkindo (6¹4'31'S, 37³3'12”E; altitude = $324 \mathrm{~m}$ asl) is a large village in the central part of the study area. Unlike, Komtonga, communities in Mkindo practice improved non-flooding canal rice-irrigation employing gravitational water supply technique.

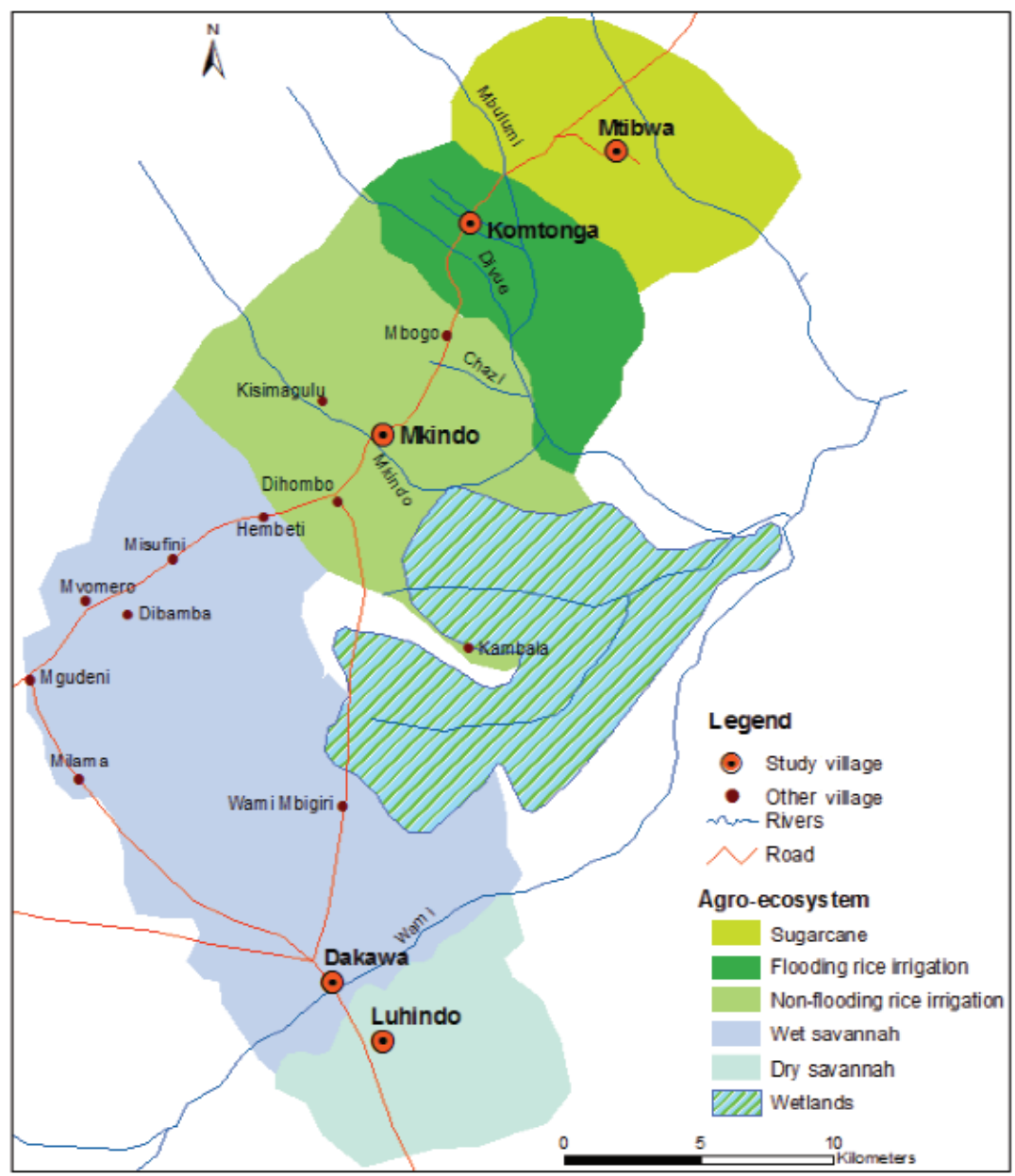

Fig. 1. Distribution of the villages and agro-ecosystems in Mvomero district, Tanzania. 
The rice-field canals are open earth-lined and distribute water from the main canal from the Mkindo River. There is a Farmers Field School at Mkindo, which since 1982, has provided farmers training on improved water control, management and agronomic practices. Houses in Mkindo are about 50$100 \mathrm{~m}$ from the adjacent rice fields.

Dakawa $\left(6^{\circ} 26^{\prime} 28^{\prime}\right.$ 'S, 37²0'35'E; altitude $=360$ $\mathrm{m}$ asl) is a big roadside village along the MorogoroDodoma highway. The village is characterised by a wet savannah type of ecosystem and maize farming is the predominant agricultural activity. Human settlements are adjacent to their respective maize farms.

Luhindo village $\left(6^{\circ} 27^{\prime} 46^{\prime \prime}\right.$ S, 37³3'12”E; altitude $=293 \mathrm{~m}$ asl) is located in the south-eastern part of the study area characterised by dry savannah type of ecosystem. Most of the area in the village is covered with short grass, trees and shrubs that provide a wide range of pasture for livestock grazing. The village is inhabited mainly by pastoralists keeping cattle, sheep and goats.

\section{Mosquito collection}

Adult mosquitoes were sampled monthly using a total of 15 index houses (three houses per village). Collections were done on three consecutive nights from August 2004 to July 2005. House selection for mosquito collection took into consideration the settlement patterns. The sentinel houses were of similar construction to avoid the effect of variability caused by differences in construction. Mosquito collections were done using Centers for Disease Control (CDC) light traps (J. W. Hock Ltd, Gainesville, Florida, USA). For operation, each light trap was hung at the top of the foot-end of the bed with an adult person sleeping under untreated mosquito net (Mboera et al., 1998). The traps were set at 18:00 hours and collected the following morning at 06:00 hours. Inquiries were made as to whether the trap fan and light had both worked all night, and catches from faulty traps were discounted.

\section{Ethical consideration}

The Medical Research Coordination Committee of the National Institute for Medical Research granted ethical clearance for the study (NIMR/HQ/R.8a/Vol.IX/297). A verbal consent was obtained from the owners of the houses where mosquito trapping was done.

\section{Anopheline mosquito identification and processing}

Collected mosquitoes were kept in cool boxes and brought to a field laboratory for identification and further processing. At the laboratory, mosquitoes were anaesthetised, sorted, identified morphologically to species level (Gillies and De Meillon, 1968; Gillies and Coetzee, 1987) and counted. Parity of female An. funestus and An. gambiae s.l. from a sample of unfed mosquitoes were determined using the conventional technique as described by Detinova (1962). The presence of malaria sporozoites was determined by examining the salivary glands under a microscope (WHO, 1975).

\section{Data analysis}

Data were entered in EpiInfo database version 6 (Centres for Disease Control and Prevention, Atlanta, GA, USA) and further analysis was done using STATA version 6 (Stata Corp, 2001) and SAS version 9.1 (SAS Institute Inc.). The number of mosquitoes collected per house was transformed to $\log _{10}(n+1)$ before analysis. The parity rates were determined as the proportion of Anopheles found to be parous and the sporozoite rates were inferred from the proportion of human biting mosquitoes found to be infected under microscopy. The human biting rates were calculated as the number of mosquitoes biting per person per night using the formula by Lines et al. (1991). Converting the trap catches to estimate bites per person and multiplying by the sporozoite rates gave estimates of the EIR per night. The annual EIR was then determined by multiplying the mean number of human bites per night by the sporozoite rate and by 365 days. 
Table 1. Species composition and number (\%) of mosquitoes collected in five study villages/agro-ecosystems in Mvomero.

\begin{tabular}{|c|c|c|c|c|c|c|}
\hline Village & Agro-ecosystem & An. gambiae & An. funestus & $C x$. quinquefasciatus & Others & Total \\
\hline Mtibwa & Sugarcane & $1,756(51.8)$ & $15(0.4)$ & $1,531(45.1)$ & $89(2.6)$ & 3,391 \\
\hline Komtonga & Flooding rice irrigation & $14,101(74.0)$ & $3,821(20.1)$ & $811(4.3)$ & $315(1.7)$ & 19,048 \\
\hline Mkindo & Non-flooding rice irrigation & $2,105(42.9)$ & $69(1.4)$ & $2,551(52.0)$ & $184(3.7)$ & 4,909 \\
\hline Dakawa & Wet savannah & $1,655(29.2)$ & $195(3.4)$ & $3,554(62.7)$ & $264(4.7)$ & 5,668 \\
\hline Luhindo & Dry savannah & $1,418(52.8)$ & $195(7.3)$ & $911(33.9)$ & $162(6.0)$ & 2,686 \\
\hline Total & & $21,035(58.9)$ & $4,295(12.0)$ & $9,358(26.2)$ & $1,014(2.8)$ & 35,702 \\
\hline
\end{tabular}

Analysis of variance was used to determine differences in biting rates, sporozoite rates, and EIR between agro-ecosystems. All tests were done at 5\% level of significance. Repeated measures and multivariate analysis (using Wilk's Lambda) were used to identify any significant differences on the number and proportion of parous and infective mosquitoes between months of collection, villages or the anopheline species. The least square means (LSM) were calculated and the Tukey procedure was used to conduct a multiple pairwise comparisons between months and villages.

\section{Results}

\section{Mosquito species abundance and parity rates}

A total of 35,702 female mosquitoes were collected. An. gambiae s.l. accounted for $58.9 \%$ of the mosquitoes collected. Significantly larger numbers of anophelines were collected from traditional flooding rice irrigation $(17,922 / 25,330 ; 70.7 \%)$ than in non-flooding canal rice irrigation $(2,174 / 25,330 ; 8.6 \%)$, sugarcane $(1,771 / 25,330$; $7.0 \%)$ wet savannah $(1,850 / 25,330 ; 7.3 \%)$ and dry savannah ecosystems $(1,613 / 25,330 ; 6.4 \%)$. Over half of the mosquitoes collected in Mkindo (52.0\%) and Dakawa $(62.7 \%)$ were Culex quinquefasciatus (Table 1).

The total mean number of An. gambiae s.l. was significantly higher than that of An. funestus ( $\mathrm{P}<0.001)$. The geometric mean density of An. funestus and An. gambiae s.l. was 3.5 and 5.0 per house per night, respectively. The combined density was 5.1 mosquitoes per house per night.
The overall mean anopheline mosquito density was high during the short rains (October-December 2004) and end of long rains (May 2005). Peak biting density for An. funestus was observed during the short rains of November-December 2004 whereas that of $A n$. gambiae s.l. was higher throughout the year with a peak during the long rains of April-May 2005 (Fig. 2).

Most $(75.0 \%)$ parous An. gambiae s.l. were collected in the sugarcane ecosystem followed by dry savannah $(52.3 \%)$ ecosystem. An. gambiae s.l. mosquitoes with the lowest parity rate $(41.1 \%)$ were collected from the non-flooding rice irrigation ecosystem. An. funestus with the highest parity rate were collected from the wet savannah $(75.0 \%)$; followed by sugarcane $(62.5 \%)$, traditional flooding rice irrigation $(55.3 \%)$, non-flooding canal rice irrigation $(51.3 \%)$ and dry savannah $(50.0 \%)$. On average, a higher parity rate was observed in

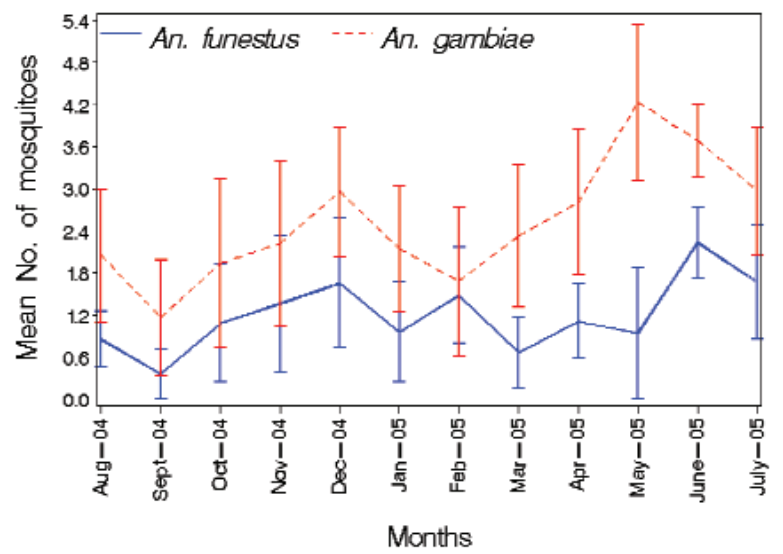

Fig. 2. Monthly geometric mean number of Anopheles gambiae s.l. and An. funestus in Mvomero district. 
An. funestus $(55.4 \%)$ than in An. gambiae s.l. $(49.3 \%)$. The overall parity rate in An. gambiae s.l. differed between months of collection $(\mathrm{P}=0.002)$ but not between ecosystems $(\mathrm{P}=0.112)$. Likewise, in An. funestus, the parity rates differed significantly $(\mathrm{P}=0.045)$ between months of collection but not between ecosystems $(\mathrm{P}=0.106)$.

\section{Sporozoite and entomological inoculation rates}

Overall sporozoite rate in An. gambiae s.l. was higher $(68 / 2,025 ; 3.4 \%)$ than that in An. funestus $(10 / 434 ; 2.3 \%)$. However, the difference was not significant $(\mathrm{P}=0.165)$. Highest mean sporozoite rate $(10 / 236 ; 4.2 \%)$ was recorded in An. gambiae s.l. collected in dry savannah ecosystem. None of the An. gambiae s.l. collected in sugarcane ecosystem was infected with malaria sporozoite. An overall $81.5 \%$ of the difference in sporozoite rate between the villages was observed $(\mathrm{P}<0.001)$. Sporozoite-infected An. funestus were only collected in flooding rice irrigation ecosystem. In all villages, the biting by $A n$. gambiae s.l. and An. funestus were experienced throughout the year (Table 2). A larger propotion of An. gambiae s.l. infected with malaria sporozoites were collected end of the long rainy season (May 2005). None of the anopheline mosquitoes collected during March 2005 was infective.

In the flooding rice irrigation ecosystem infective An. gambiae s.l. were collected throughout the 12month period, with peaks in August-September 2004 and February 2005. Infective An. gambiae in non-flooding rice irrigation were collected in
November 2004, while in the other ecosystems they were collected in May 2005 (wet savannah), May and June 2005 (dry savannah) and June (sugarcane). Infective An. funestus mosquitoes were only collected in flooding rice irrigation ecosystem, showing two peaks in October-January and MayJune.

Overall human biting rates in An. gambiae s.l. and $A n$. funestus were 175.3 and 35.8 bites per person per night, respectively. Seasonal pattern in human biting rate was observed in all villages. It was highest during the long rains (March-June) and lowest during the dry season of January and February. The highest human biting rate per person per night in An. gambiae s.l. (495.7) and EIR (16.2) were recorded at the end of rainy season in May 2005. In An. funestus the highest human biting rate (121.3) and EIR (3.4) were observed during the short rains of December 2004. The average EIR per person per night was estimated at 6.0 and 0.8 for An. gambiae s.l. and An. funestus, respectively (Table 3).

The daily and annual EIRs varied from one agro-ecosystem to another. The overall annual EIR for the study area was 728 and 12 infective bites (i.b.) for An. gambiae s.l. and An. funestus, respectively. People living in Komtonga (flooding rice irrigation ecosystem) were receiving the highest annual EIR from either single species ( $A n$. gambiae $=1,350$ infective bites; An. funestus = 270 infective bites) or both species combined ( $A n$. gambiae $+A n$. funestus $=1626$ infective bites) than their contemporaries in the other ecosystems (Table 4).

Table 2. Sporozoite rate (\%) in Anopheles gambiae s.l. and An. funestus by village and agro-ecosystem in Mvomero district, Tanzania.

\begin{tabular}{lllll}
\hline Village & Agro-ecosystem & An. gambiae s.l. & An. funestus & Total (An. gambiae + An. funestus) \\
\hline Komtonga & Flooding rice irrigation & $54 / 1,447(3.7)$ & $10 / 399(2.5)$ & $64 / 1,846(3.5)$ \\
Mkindo & Non-flooding rice irrigation & $3 / 226(1.3)$ & $0 / 20(0.0)$ & $3 / 246(1.2)$ \\
Dakawa & Wet savannah & $1 / 107(0.9)$ & $0 / 9(0.0)$ & $1 / 116(0.9)$ \\
Luhindo & Dry savannah & $10 / 236(4.2)$ & $0 / 1(0.0)$ & $10 / 237(0.4)$ \\
Mtibwa & Sugarcane & $0 / 9(0.0)$ & $0 / 5(0.0)$ & $0 / 14(0.0)$ \\
Total & & $68 / 2,025(3.4)$ & $10 / 434(2.3)$ & $78 / 2,459(3.2)$ \\
\hline
\end{tabular}


Table 3. Overall monthly mean number of mosquitoes, estimated human biting rate (HBR) per night and entomological inoculation rate (EIR) per night of Anopheles gambiae s.l. and An. funestus in Mvomero district, Tanzania.

\begin{tabular}{|c|c|c|c|c|c|c|c|c|}
\hline \multirow[t]{2}{*}{ Month } & \multicolumn{2}{|c|}{$\begin{array}{l}\text { Mean no. of mosquitoes } \\
\text { collected/person/trap }\end{array}$} & \multicolumn{2}{|c|}{ Estimated HBR } & \multicolumn{2}{|c|}{ Sporozoite rate } & \multicolumn{2}{|c|}{ EIR } \\
\hline & An. gambiae & An. funestus & An. gambiae & An. funestus & An. gambiae & An. funestus & An. gambiae & An. funestus \\
\hline Aug 2004 & 68.6 & 4.0 & 102.9 & 6.0 & 1.5 & 0.0 & 1.5 & 0.0 \\
\hline Sep 2004 & 92.9 & 6.0 & 139.4 & 9.0 & 4.2 & 0.0 & 5.8 & 0.0 \\
\hline Oct 2004 & 156.8 & 42.2 & 235.2 & 63.3 & 3.6 & 3.2 & 8.4 & 2.0 \\
\hline Nov 2004 & 100.8 & 49.9 & 151.2 & 74.9 & 1.9 & 1.1 & 2.9 & 0.8 \\
\hline Dec 2004 & 121.2 & 80.9 & 181.8 & 121.4 & 2.6 & 2.8 & 4.8 & 3.4 \\
\hline Jan 2005 & 51.5 & 15.0 & 77.3 & 22.5 & 5.4 & 6.9 & 4.2 & 1.6 \\
\hline Feb 2005 & 44.3 & 10.5 & 66.5 & 15.7 & 12.0 & 3.5 & 8.0 & 0.5 \\
\hline Mar 2005 & 94.2 & 3.3 & 141.3 & 5.0 & 0.0 & 0.0 & 0 & 0.0 \\
\hline Apr 2005 & 171.3 & 3.3 & 256.9 & 5.0 & 1.1 & 0.0 & 2.7 & 0.0 \\
\hline May 2005 & 330.5 & 33.9 & 495.7 & 50.9 & 3.3 & 1.6 & 16.2 & 0.8 \\
\hline Jun 2005 & 74.5 & 18.9 & 111.8 & 28.3 & 5.7 & 4.8 & 6.4 & 1.4 \\
\hline Jul 2005 & 95.7 & 17.7 & 143.5 & 26.6 & 2.9 & 0.0 & 4.1 & 0.0 \\
\hline Total & 116.9 & 23.9 & 175.3 & 35.8 & 3.4 & 2.3 & 6.0 & 0.8 \\
\hline
\end{tabular}

Table 4. Estimated mean human biting rate (HBR) per night and annual entomological inoculation rate (AEIR) by study village and agro-ecosystem in Mvomero district, Tanzania.

\begin{tabular}{|c|c|c|c|c|c|c|c|}
\hline \multirow[t]{2}{*}{ Village } & \multirow[t]{2}{*}{ Agro-ecosystem } & \multicolumn{2}{|c|}{ An. gambiae s.l. } & \multicolumn{2}{|c|}{ An. funestus } & \multicolumn{2}{|c|}{ An. gambiae + An. funestus } \\
\hline & & HBR/night & AEIR & HBR/night & AEIR & HBR/night & AEIR \\
\hline Komtonga & Flooding rice irrigation & 195.9 & 1350.5 & 53.1 & 270.1 & 248.9 & 1626.3 \\
\hline \multirow[t]{2}{*}{ Mkindo } & Non-flooding rice & 30.2 & 60.6 & 1.0 & 0 & 31.2 & 58.4 \\
\hline & irrigation & 19.7 & 159.6 & 2.7 & 0 & 22.4 & 182.5 \\
\hline Luhindo & Dry savannah & 23.0 & 35.2 & 2.7 & 0 & 25.7 & 37.5 \\
\hline Dakawa & Wet savannah & 24.4 & 0 & 0.2 & 0 & 24.6 & 0 \\
\hline Mtibwa & Sugarcane & 58.5 & 727.5 & 11.9 & 55.7 & 70.4 & 413.5 \\
\hline
\end{tabular}

\section{Discussion}

Malaria in Mvomero district, Tanzania, is transmitted predominantly by An. gambiae s.l. and An. funestus. Indeed, the former species represents more than half of the malaria vectors in the area with variation in density between villages, and hence from one agroecosystem to another and between seasons. The variation in monthly mosquito density was less marked in flooding rice irrigation ecosystem (Komtonga), where the two malaria vector species were abundant throughout the year. The all-year round availability of water bodies at Komtonga was providing breeding sites for the two species of mosquitoes.
The variation in the abundance between An. gambiae s.l. and An. funestus can be explained by their differences in ecological requirements. An. gambiae s.l. typically breed in very transient habitats like shallow sunlit fresh water pools or human-made habitats (Shililu et al., 1998), though they may also be common in rice-fields (Robert et al., 1998; Minakawa et al., 1999). In contrast, An. funestus breed mainly in marshes and other types of sheltered habitats that contain vegetation (Gillies and De Meillon, 1968; Gillies and Coetzee, 1987), typical of the ecosystem in Komtonga village. The large numbers of $C x$. quinquefasciatus in Mkindo and Dakawa indicate the availability of favourable 
breeding sites, most likely pit latrines, which were very common in both villages (data not shown). Cx. quinquefasciatus usually develops mainly in habitats containing highly polluted water rich in organic matter that larvae can use for nourishment (Subra, 1981).

The higher parity rate in An. gambiae s.l. population in the sugarcane ecosystem was likely to be due to the low number of mosquitoes collected, indicating a low recruitment rate. However, the mosquitoes were likely to have lived long enough to have taken at least a blood meal. The presence of An. gambiae s.l. with low parity rate in non-flooding rice irrigation ecosystem suggests that new emerging mosquitoes were continuously more abundant than the older ones. The monthly variation in parity rate in both An. gambiae s.l. and An. funestus is most likely to be associated with the seasonal abundance of mosquito breeding sites. The temporal and spatial mosquito abundance and parity rates in Mvomero district is likely to be influenced by environmental variables such as rainfall and availability of either temporary or permanent water bodies.

There were variations in the biting rate and malaria transmission intensity between the five agroecosystems. Such variations were clear despite the relative proximity of the villages within short distances. Overall, malaria transmission was highest in rice irrigation ecosystems than in other ecosystems. In the two rice irrigation ecosystems, infective mosquitoes were caught throughout the year except during the start of the long rains in March; indicating a continuous presence of mature female mosquitoes. According to a model by Smith et al. (2004) the human biting rate is highest shortly after the mosquito densities peak, near breeding sites where adult mosquitoes emerge, and around the edges of areas where humans are aggregated. These sources of spatial and temporal heterogeneity in the distribution of mosquito populations are associated with the variability in the human biting rate, the proportion of mosquitoes that are infectious, and in the risk of human infection (Smith et al., 2004).

Similar to mosquito density, the annual EIR esti- mates at the five sites displayed marked temporal and spatial variations, with likelihood of communities in flooding rice irrigation ecosystem experiencing the highest EIR throughout the year. Similar variations in malaria transmission intensity have been observed elsewhere in Tanzania (Ijumba and Lindsay, 2001), Ghana (Appawu et al., 2004) and Côte d'Ivoire (Koudou et al., 2005; Matthys et al., 2006). In our study, the highest EIR in the flooding rice irrigation and the lowest EIR in sugarcane ecosystem could be explained by differences in the ecological settings of the two sites, and more specifically the availability of favourable breeding sites. It has already been observed that irrigated rice cultivation enhances population development of many malaria mosquito species in sub-Saharan Africa (Chandler et al., 1975; Coosemans, 1985; Robert et al., 1985; Lacey and Lacey, 1990; Dossou-Yovo et al., 1994; Briët et al., 2003) and has been associated with high malaria transmission (Appawu et al., 2004; Dolo et al., 2004; Diuk-Wasser et al., 2005; Koudou et al., 2005). This is because rice irrigation provides ideal breeding sites for the major malaria vectors in Africa (Carnevale et al., 1999; Appawu et al., 2004). The generally low EIR for An. funestus compared with An. gambiae s.l. in Mvomero suggests that the former species plays a minor role in malaria transmission in the area.

Studies in East and West Africa indicate that communities in irrigated zones are at higher risk of malaria mosquito infective bites than in non-irrigated zones (Ijumba, 1997). Several studies have consequently compared transmission among different ecological zones and even among villages separated only by short distances within the same area (Dolo et al., 2004; Okello et al., 2006). These and the present study confirm that malaria transmission is heterogeneous even at micro-ecological levels, consistent with the high degree of ecological diversity of the area.

Seasonal transmission was observed in almost all ecosystems, with most of the transmission at the end of the long rains in May. It has been observed that vector species behaviour, density and the EIRs are 
dependent on seasonal changes in environmental variables (Koudou et al., 2010). However, the seasonal variation was less marked in Komtonga (characterised by permanent swamps), most likely, because, mosquito abundance was not directly associated with rainy season.

The difference in Anopheles mosquito densities and transmission intensities in different villages is likely to have been contributed to agro-ecosystems and farming practices. Malaria transmission intensity was lowest in sugarcane ecosystem. A negative impact of large-scale sugarcane cultivation on mosquito productivity and malaria has also been reported in northern Tanzania (Ijumba et al., 2002). Similar to our findings, only a few incidences of increase in malaria has been associated with sugarcane in Africa because it is known that a properly maintained sugarcane irrigation system does not offer appropriate breeding sites for An. gambiae s.l. (Packard, 1986). Although sugarcane requires irrigation for optimal growth, the plant is very susceptible to water-logging and therefore needs efficient drainage (Arnon, 1972). During this study irrigation in the sugarcane plantations was either overhead (using sprinklers) or by use of well drained water canals.

Malaria transmission intensity in non-flooding rice irrigation was lower than in flooding rice irrigation villages. This indicates that water management is likely to have an impact on mosquito productivity. Water management such as intermittent irrigation as well as adaptation of farming practices may significantly reduce the number of breeding sites in rice fields (Keiser et al., 2002; Klinkenberg et al., 2005). Contrary to our findings, some other studies in East and West Africa failed to establish a direct association between irrigated fields and transmission intensity (Ijumba et al., 2002; Dolo et al., 2004). For instance, in Côte d'Ivoire, despite high anopheline densities in areas bordering rice cultivation, Dossou-Yovo et al. (1994) reported low sporozoite rates indicating that rice fields did not seem to have increased malaria transmission. More recent investigations in Côte d'Ivoire, however, showed that irrigated rice farming was strongly associated with malaria transmission, and entomological indictors were tightly linked to changing patterns of irrigated rice farming (Koudou et al., 2005, 2010).

Malaria transmission intensity in Mvomero is closely related to prevalence of malaria in the population. In a series of parallel studies in Mvomero district, the prevalence of malaria parasitaemia was highest in traditional flooding rice irrigation ecosystem where the highest EIR in the current study was observed (Mboera et al., 2007). Similar observations have been reported in north-eastern Tanzania where it was observed that where the mean annual EIR was high, the mean annual parasite prevalence was also high (Ellman et al., 1998). The inoculation rates observed in the present study were generally comparable with records from most entomological surveys carried out across the coastal and northeastern regions of Tanzania, where transmission is perennial (Temu et al., 1998; Mboera, 2000; Maxwell et al., 2003).

Findings of this study support the evidence that malaria transmission risk varies between regions and even between neighbouring localities (Temu et al., 1998; Ye' et al., 2007). This means, knowledge of malaria risk at a local level is likely to provide more reliable information that is crucial for specific area control strategies. This study therefore, confirms previous studies in demonstrating the need to generate spatial and temporal data on transmission intensity on smaller scales taking into consideration agro-ecosystems that will identify area-specific transmission intensity to guide targeted control of malaria interventions. In conclusion, assessing malaria transmission risk within micro- and agroecological zones provides a detailed picture of the spatial distribution of the disease which is likely to require a specific package of interventions.

\section{Acknowledgements}

We are grateful to Aza Kimambo, Abdalla Telaki, Benjamin Chambika and Joyceline Nyongole for their excellent technical assistance and conscientious work. We thank 
the owners of the 15 houses for their excellent co-operation in mosquito collection. This study received financial support from the International Water Management Institute through the Systemwide Initiative in Malaria and Agriculture and the Ministry of Health and Social Welfare (MoHSW), Tanzania.

\section{References}

Appawu M, Owusu-Agyei S, Dadzie S, Asoala V, Anto F, Koram K, Rogers W, Nkrumah F, Hoffman SL, Fryauff DJ, 2004. Malaria transmission dynamics at a site in northern Ghana proposed for testing malaria vaccines. Trop Med Int Health 9, 164-170.

Arnon I, 1972. Crop Production in Dry Regions. Leonard Hill, London, UK.

Briët OJT, Dossou-Yovo J, Akodo E, van de Glesen N, Teuscher TM, 2003. The relationship between Anopheles gambiae density and rice cultivation in the savannah zone and forest zone of Côte d'Ivoire. Trop Med Int Health 8, 439-448.

Carnevale P, Guillet P, Robert V, Fontenille D, Doannio J, Coosemans M, Mouchet J, 1999. Diversity of malaria in rice growing areas of Afrotropical region. Parassitologia 41, 273-276.

Chandler JA, Highton RB, Hill MN, 1975. Mosquitoes of the Kano plain, Kenya 1. Results of indoor collections in irrigated and non-irrigated areas using human bait and light traps. J Med Entomol 12, 504-510.

Coosemans MH, 1985. Comparison of malarial endemicity in a rice-growing zone and in a cotton-growing zone in the Rusizi Plain, Burundi. Ann Soc Belg Med Trop 65, 187-200.

Detinova T, 1962. Age-grouping methods in Diptera of medical importance with special reference to some vectors of malaria. World Health Organization, Geneva, Switzerland. Diuk-Wasser MA, Toure MB, Dolo G, Bagayoko M, Sogoba N, Traore SF, Manoukis N, Taylor CE, 2005. Vector abundance and malaria transmission in rice-growing villages in Mali. Am J Trop Med Hyg 72, 725-731.

Dolo G, Briët OJ, Dao A, Traore SF, Bouare M, Sogoba N, Niare O, Bagayogo M, Sangare D, Teuscher T, Tourre YT, 2004. Malaria transmission in relation to rice cultivation in the irrigated Sahel of Mali. Acta Trop 89, 147-159.

Dongus S, Nyika D, Kannady K, Mtasiwa D, Mshinda H, Gosoniu L, Drescher A, Tanner M, Killeen GF, Castro MC,
2009. Urban agriculture and Anopheles habitats in Dar es Salaam, Tanzania. Geospat Health 3, 189-210.

Dossou-Yovo J, Doannio J, Riviere F, Duval J, 1994. Rice cultivation and malaria transmission in Bouake City (Côte d'Ivoire). Acta Trop 57, 91-94.

Ellman R, Maxwell C, Finch R, Shayo D, 1998. Malaria and anaemia at different altitudes in the Muheza district of Tanzania: childhood morbidity in relation to level of exposure to infection. Ann Trop Med Parasitol 92, 741-753.

Gillies MT, Coetzee M, 1987. A supplement to the Anophelinae of Africa south of the Sahara (Afrotropical Region), Johannesburg. Publication of the South African Institute for Medical Research, Johannesburg, South Africa. Gillies MT, De Meillon B, 1968. The Anophelinae of Africa south of the Sahara (Ethiopian Zoogeographical Region) (2nd Ed.), Johannesburg. Publication of the South African Institute for Medical Research, Johannesburg, South Africa. Githeko AK, Service MW, Mbogo CM, Atiel FK, Juma FO, 1993. Plasmodium falciparum sporozoite and entomological inoculation rates in the Ahero irrigation scheme and the Miwani sugar-belt in western Kenya. Ann Trop Med Parasitol 87, 379-391.

Ijumba JN, 1997. The impact of rice and sugarcane irrigation on malaria transmission in the lower Moshi area in northern Tanzania. PhD Thesis, Danish Bilharziasis Laboratory, University of Copenhagen, Denmark.

Ijumba JN, Lindsay SW, 2001. Impact of irrigation on malaria in Africa: paddies paradox. Med Vet Entomol 15, 1-11.

Ijumba JN, Shenton FC, Clarke SE, Mosha FW, Lindsay SW, 2002. Irrigated crop production is associated with less malaria than traditional agricultural practices in Tanzania. Trans R Soc Trop Med Hyg 96, 476-480.

Keiser J, Utzinger J, Singer BH, 2002. The potential of intermittent irrigation for increasing rice yields, lowering water consumption, reducing methane emissions, and controlling malaria in African rice fields. J Am Mosq Control Assoc 18, 329-340.

Klinkenberg E, McCall PJ, Hastings IM, Wilson MD, Amerasinghe FP, Donnelly MJ, 2005. Malaria in irrigated crops, Accra Ghana. Emerg Infect Dis 11, 1290-1293.

Koudou BG, Doumbia M, Janmohamed N, Tschannen AB, Tanner M, Hemingway J, Utzinger J, 2010. Effects of seasonality and irrigation on malaria transmission in two villages in Côte d'Ivoire. Ann Trop Med Parasitol 104, 109-121. 
Koudou BG, Tano Y, Doumbia M, Nsanzabana C, Cissé G, Girardin O, Dao D, N'Goran EK, Vounatsou P, Bordmann G, Keiser J, Tanner M, Utzinger J, 2005. Malaria transmission dynamics in central Côte d'Ivoire: the influence of changing patterns of irrigated rice agriculture. Med Vet Entomol 19, 27-37.

Lacey LA, Lacey CM, 1990. The medical importance of riceland mosquitoes and their control using alternatives to chemical insecticide. J Am Mosq Control Assoc 6, 1-93.

Lines JD, Curtis CF, Wilkes TJ, Njunwa KJ, 1991. Monitoring human biting mosquitoes in Tanzania with light-traps hung beside mosquito nets. Bull Entomol Res 81, 77-84.

Matthys B, Vounatsou P, Raso G, Tschannen AB, Becket EG, Gosoniu L, Cissé G, Tanner M, N'Goran EK, Utzinger J, 2006. Urban farming and malaria risk factors in a mediumsized town in Côte d'Ivoire. Am J Trop Med Hyg 75, 12231231.

Maxwell CA, Chambo W, Mwaimu M, Magogo F, Carneiro IA, Curtis CF, 2003. Variation of malaria transmission and morbidity with altitude in Tanzania and with introduction of alphacypermethrin treated nets. Malaria J 2, 28.

Mboera LE, Kihonda J, Braks MA, Knols BJG, 1998. Influence of Centers for Disease Control light trap position, relative to a human-baited bed net, on catches of Anopheles gambiae and Culex quinquefasciatus in Tanzania. Am J Trop Med Hyg 59, 595-596.

Mboera LEG, 2000. Fifty Years of Health Research in Tanzania. Annotated Bibliography. DUP (1996) Ltd, 373 pp. Mboera LEG, Mlozi MRS, Senkoro KP, Rumisha SF, Mayala BK, Shayo EH, Senkondo E, Mwingira VS, Maerere A, 2007. Malaria and Agriculture in Tanzania: Impact of Land Use and Agricultural Practices on Malaria Burden in Mvomero district. National Institute for Medical Research, Tanzania.

Minakawa N, Mutero CM, Githure JI, Beier JC, Yan G, 1999. Spatial distribution and habitat characterization of anopheline mosquito larvae in Western Kenya. Am J Trop Med Hyg 61, 1010-1016.

Mutero C, McCartney M, Boelee E, 2006. Understanding the links between agriculture and health: agriculture, malaria and water-associated diseases. Brief 6. International Food Policy Research Institute, Washington DC, USA.

Okello PE, van Bortel W, Byaruhanga AM, Correwyn A,
Roelants P, Talisuna A, D’Alessandro U, Coosemans M, 2006. Variation in malaria transmission intensity in seven sites throughout Uganda. Am J Trop Med Hyg 75, 219225.

Oomen JMV, De Wolf J, Jobin WR, 1988. Health and Irrigation. Incorporation of Disease Control Measures in Irrigation, a Multi Faceted Task in Design, Construction, Operation. Volume 2. ILRI Publication No. 45. International Institute for Land Reclamation and Improvement, Wageningen, the Netherlands.

Packard RM, 1986. Agricultural development, migrant labor and the resurgence of malaria in Swaziland. Soc Sci Med 22, 861-867.

Robert V, Awono-Ambene HP, Thioulouse J, 1998. Ecology of larval mosquitoes, with special reference to Anopheles arabiensis (Diptera: Culicidae) in market-garden wells in urban Dakar, Senegal. J Med Entomol 35, 948-955.

Robert V, Gazin P, Boudin C, Molez JF, Ouedraogo V, Carnevale P, 1985. The transmission of malaria in wooded savanna zone and a rice-growing zone in the vicinity of Bobo Dioulasso (Burkina Faso). Ann Soc Belg Med Trop 65, 201-214.

Shililu JI, Maier WA, Seitz HM, Orago AS, 1998. Seasonal density, sporozoite rates and entomological inoculation rates of Anopheles gambiae and Anopheles funestus in a high-altitude sugarcane growing zone in western Kenya. Trop Med Int Health 3, 706-710.

Shililu J, Ghebremeskel T, Mengistu S, Fekadu H, Zerom M, Mbogo C, Githure J, Novak R, Brantly E, Beier J, 2003. Highly seasonal variation in entomologic inoculation rates in Eritrea, a semi-arid region of unstable malaria in Africa. Am J Trop Med Hyg 69, 607-613.

Smith DL, Dushoff J, McKenzie FE, 2004 The risk of a mosquito-borne infection in a heterogeneous environment. PLoS Biol 2, e368.

Subra R, 1981. Biology and control of Culex pipiens quinquefasciatus, Say, 1823 (Diptera, Culicidae) with special reference to Africa. Insect Sci Appl 4, 319-338.

Temu EA, Minjas JN, Coetzee M, Hunt RH, Shiff CJ, 1998. The role of four anopheline species (Diptera: Culicidae) in malaria transmission in coastal Tanzania. Trans R Soc Trop Med Hyg 92, 152-158.

WHO/FAO/UNEP, 2008. Effects of agricultural development on vector-borne diseases. Working papers of 7 th Annual 
Meeting, Joint WHO/FAO/UNEP Panel of Experts on Environmental Management for Vector Control. World Health Organization, Geneva, Switzerland.

WHO, 1975. Manual on Practical Entomology in Malaria:

Part II - Methods and Techniques. WHO Offset Publication
No. 13. World Health Organization, Geneva, Switzerland Ye' Y, Kyobutungi C, Louis VR, Sauerborn R, 2007. Microepidemiology of Plasmodium falciparum malaria: Is there any difference in transmission risk between neighbouring villages? Malaria J 6, 46. 